\title{
Treatment effects of stimulant medication in young boys with fragile $X$ syndrome
}

\author{
Jane E. Roberts • Margot Miranda $•$ Maria Boccia • \\ Heather Janes • Bridgette L. Tonnsen • \\ Deborah D. Hatton
}

Received: 25 November 2010 / Accepted: 24 May 2011 /Published online: 14 June 2011

(C) Springer Science+Business Media, LLC 2011

\begin{abstract}
Fragile X syndrome (FXS) is the most common inherited form of intellectual disability and is caused by a CGG repeat expansion at Xq27.3 on the FMR1 gene. The majority of young boys with FXS display poor attention and hyperactivity that is disproportionate to their cognitive disability, and approximately $70 \%$ meet diagnostic criteria for attention-deficit/hyperactivity disorder. Psychopharmacology is employed with $82 \%$ of young males 5-17 years of age, with stimulant medication as the most common medication prescribed. This study evaluated the effects of stimulant medication on the academic performance, attention, motor activity, and psychophysiological arousal of boys with FXS, as well as the concordance of effects within individuals. Participants in this study included 12 boys with FXS who were treated with stimulants. Participants completed videotaped academic testing on two consecutive days and were randomly assigned to be off stimulants for
\end{abstract}

J. E. Roberts $(\bowtie) \cdot$ B. L. Tonnsen

Department of Psychology, University of South Carolina,

1512 Pendleton Street,

Columbia, SC 29028, USA

e-mail: jerobert@mailbox.sc.edu

M. Miranda $\cdot$ H. Janes

FPC Child Development Institute,

The University of North Carolina at Chapel Hill,

Chapel Hill, NC, USA

\section{Boccia}

Gordon-Conwell Theological Seminary,

Charlotte, NC, USA

D. D. Hatton

Department of Special Education, Vanderbilt University,

Nashville, TN, USA
1 day and on stimulants the other day. On each day, multiple measures including academic performance, behavior regulation, and psychophysiological arousal were collected. Approximately $75 \%$ of participants performed better on attention and academic measures, and $70 \%$ showed improved physiological regulation while on stimulant medication. A high degree of concordance among measures was found. Lower intelligence quotient (IQ), but not age, correlated with greater improvements in in-seat behavior. IQ and age did not relate to on-task behaviors. The frequency and magnitude of response to stimulant medication in boys with FXS is higher than those reported for most children with non-specific intellectual disabilities and autism spectrum disorder.

Keywords Fragile X FMR1 - Mental retardation . Medication $\cdot$ Stimulants

\section{Introduction}

Fragile X syndrome (FXS) is the most common inherited form of intellectual disability, caused by a CGG trinucleotide repeat expansion on the fragile $\mathrm{X}$ mental retardation 1 (FMR1) gene at Xq 27.3. The FMR1 gene is associated with production of FMR1 protein (FMRP) that appears essential for normal brain functioning (Tsiouris and Brown 2004). Individuals with 50-200 CGG repeats have the fragile X premutation. Approximately 1:256 females are premutation carriers who have a $50 \%$ chance of transmitting FXS to their children, with the chance of expansion to the full mutation increasing across generations. The full mutation describes persons with $>200$ CGG repeats with prevalence estimates of 1:4,000 males and 1:8,000 females that are affected (Backes et al. 2000). Females are typically more mildly affected given random $\mathrm{X}$-inactivation. 
Phenotypic characteristics of FXS

Distinct physical, cognitive, and behavioral characteristics are associated with the FXS full mutation. Physical features include a long, narrow face, prominent ears, hyper-extensible joints, and machroorchidism (Tsiouris and Brown 2004). While cognitive abilities vary, most males have a moderate intellectual disability (Hagerman et al. 1994). Common behavioral features of children with FXS include inattention, impulsivity, social anxiety, gaze aversion, obsessive-compulsive disorder-like and perseverative behaviors, aggression, self-injury, and stereotypies (Bailey et al. 1998; Berry-Kravis and Potanos 2004; Hagerman et al. 2002).

The primary symptom cluster of problem behaviors in children with FXS is attention-deficit/hyperactivity disorder (ADHD), and approximately $59-70 \%$ of individuals with FXS meet Diagnostic and Statistical Manual of Mental Disorders (DSM) criteria (Backes et al. 2000; Baumgardner et al. 1995; Sullivan et al. 2006; Turk 1992). ADHD is a pervasive feature in FXS, affecting the broad cognitive spectrum of boys with borderline to normal intelligence quotient (IQ) scores (Staley-Gane et al. 1996). Studies indicate that the prevalence of ADHD in FXS is higher than rates of $7-33 \%$ for children with non-specific intellectual disability (Baumgardner et al. 1995) and is independent of mental age (Sullivan et al. 2006) and IQ (Baumgardner et al. 1995).

Gender, age, and molecular markers are associated with the prevalence and severity of ADHD in children with FXS. Consistent with community samples, ADHD is more prevalent and severe in boys than girls with FXS (Sullivan et al. 2006; Freund et al. 1993). Also, ADHD is more prevalent in FXS at younger ages, with motor activity becoming less severe during late childhood and adolescence and attention problems persisting over time (Fryns 1985; Hagerman 2002). The underlying mechanisms associated with ADHD in FXS are unknown; however, FMRP reduction has been associated with decreased attention in children with FXS (Loesch et al. 2004) and increased physiological arousal (Miller et al. 1999), suggesting that FMRP may be a molecular marker of the underlying pathophysiology of attention deficits in FXS. Lower FMRP levels are associated with neuroanatomical changes including enhanced dendritic branching and immature spines (Comery et al. 1997; Weiler and Greenough 1999), as well as altered dopamine and norepinephrine pathways (Hagerman et al. 2002; Weiler and Greenough 1999; Wang et al. 2008, 2010). Enhanced dendridic connections and potential dopamine deficits have been proposed as possible mechanisms through which stimulant medications reduce electrodermal responsiveness in individuals with FXS (Hagerman et al. 2002).
Psychopharmacologic treatment in FXS

Although recent advances have been made with regard to the development of treatments to reduce or reverse the symptoms of FXS (Hayashi et al. 2007; Zeier et al. 2009), most studies of targeted drugs to alter the FXS phenotype in humans are in early phases of clinical trials or have not been replicated (Berry-Kravis et al. 2008, 2009; Bilousova et al. 2009; Erickson et al. 2011; Paribello et al. 2010; Torrioli et al. 2008, 2010). Thus, despite these promising advances, an etiology-specific psychopharmacologic treatment in FXS is not currently available due, in large part, to insufficient controlled treatment studies and heterogeneity within FXS.

Treatment in FXS often targets symptom improvement and is multi-modal including behavioral, special educational, and non-FXS specific psychopharmacological methods (Tsiouris and Brown 2004; Berry-Kravis and Potanos 2004). Surveys estimate that $82-91 \%$ of boys with FXS 5-18 years of age use one or more medications (Berry-Kravis and Potanos 2004; Amaría et al. 2001). Stimulants are generally well tolerated in FXS and are the most commonly prescribed medication in boys with FXS (Berry-Kravis and Potanos 2004), with over two thirds of survey respondents reporting treatment with stimulants (Amaría et al. 2001). Despite their common use, only one published study has evaluated the influence of stimulant medication on behavior in children with FXS. Using a doubleblind placebo-controlled crossover design, Hagerman et al. (1988) reported that 10 of 15 children (13 boys, two girls) with FXS showed increased attention and improved social skills when taking methylphenidate (e.g., Ritalin) compared to dextroamphetamine (e.g., Dexedrine) and placebo. Amphetamine was associated with more side effects, including mood lability and irritability. Preliminary results from an unpublished study of dextroamphetamine in 24 children with FXS or other developmental disabilities reported a $50 \%$ response rate with note of increased side effects such as elevated anxiety and irritability (Riley et al. 2000). Hagerman et al. (2002) examined the electrodermal responses both on and off stimulants (methylphenidate, dextroamphetamine) in 19 children with both ADHD and FXS (15 males, four females) and a comparison group of 17 age- and IQ-matched children (13 males, four females). Although baseline responses were comparable across groups, the children with FXS displayed a more normalized electrodermal response when taking stimulants that was not shown by the comparison group, suggesting that children with FXS may be more responsive to stimulant treatment than children with non-specific intellectual disability and ADHD. Notably, interpretation of these findings is complicated due to concurrent use of other medications by approximately one third of the comparison and subjects with FXS. 
In summary, the majority of young boys with FXS display poor attention, impulsivity, and hyperactivity that interfere with their social and academic performance. Psychopharmacologic treatment using stimulants is widespread; however, there are few treatment studies regarding the use of stimulants to treat children with FXS. Existing published studies are limited by small samples that combine genders, fail to control for multiple medications, or heavily rely on parental or clinical ratings. Given reports that stimulant response may be more heterogeneous in children with intellectual disability and ADHD and is associated with increased side effects (Aman et al. 1996, 2003; Pearson et al. 2004; Scahill and Pachler 2007), additional study of stimulant medication treatment response in FXS is essential to identifying variables common and unique to FXS that can inform psychopharmacological phenotypes for specific disorders (Hagerman 1999). Two research questions guided the present study. First, what are the effects of stimulant medication on attention, motor activity, academic performance, and physiological arousal in children with FXS? Second, what is the relationship among the observed changes in these variables within individuals?

\section{Method}

Participants

Participants were recruited from an ongoing, longitudinal neuropsychological study of attention, memory, and exec- utive function in fragile $X$ syndrome (Ornstein et al. 2008). Procedures were in accordance with the Helinski Declaration and were approved by the University of North Carolina at Chapel Hill Institutional Review Board (IRB). Informed consent was obtained from the parents of all children and video tapes were archived in secured storage for future analyses in accordance with IRB procedures. The present study included 12 boys with a mean age of 8 years, 5 months (range 5-11 years) with full mutation FXS. All participants were boys currently prescribed stimulant medication (Methylphenidate or Dextroamphetamine) for attention deficits by their community-based medical practitioner. The mean nonverbal IQ for these subjects was 56.92 (range 42-76). See Table 1 for participant descriptions and medication information.

Diagnoses of ADHD were not collected, as the primary focus of this study was the effects of stimulant treatment regardless of formal diagnosis, with ADHD features conceptualized as a continuum of behaviors. However, as part of the broader longitudinal study, parents completed the Child Behavior Checklist (CBCL; Achenbach et al. 2001; Achenbach 1991), a widely-used parent report of internalizing and externalizing symptoms for preschool (ages 18 months -5 years) and school-age (6-18 years) children. Two CBCL subscales measure attention problems. On the Attention Problems subscale, which measures global problem behaviors related to attention, participants had an average T-score of 65 (range 53-75), with 50\% falling in the borderline range $(n=6)$ and $17 \%$ falling in the clinically

Table 1 Subject characteristics

\begin{tabular}{|c|c|c|c|c|c|c|c|c|c|}
\hline \multirow[t]{2}{*}{ Age (years) } & \multirow[t]{2}{*}{ IQ } & \multirow[t]{2}{*}{ Medication } & \multirow[t]{2}{*}{ Dose } & \multicolumn{2}{|l|}{ CBCL $T$ score } & \multicolumn{2}{|c|}{$\%$ Time attending } & \multicolumn{2}{|c|}{$\%$ Time out of seat } \\
\hline & & & & DSM-ADHD & $\begin{array}{l}\text { Attention } \\
\text { problems }\end{array}$ & $\begin{array}{l}\text { On } \\
\text { medication }\end{array}$ & $\begin{array}{l}\text { Off } \\
\text { medication }\end{array}$ & $\begin{array}{l}\text { On } \\
\text { medication }\end{array}$ & $\begin{array}{l}\text { Off } \\
\text { medication }\end{array}$ \\
\hline 5 & 76 & Methylphenidate & 0.10 mg/kg A.M. & 58 & $66^{\mathrm{a}}$ & 64 & 80 & 84 & 57 \\
\hline 6 & 76 & Methylphenidate & 0.10 mg/kg A.M. & $69^{\mathrm{a}}$ & $75^{\mathrm{b}}$ & 92 & 57 & 35 & 8 \\
\hline 6 & 73 & Dextroamphetamine & $0.025 \mathrm{mg} / \mathrm{kg}$ A.M. & 50 & 53 & 68 & 59 & 1 & 0 \\
\hline 7 & 54 & Methylphenidate & $0.10 \mathrm{mg} / \mathrm{kg}$ A.M. & 58 & 64 & 98 & 58 & 0 & 37 \\
\hline 8 & 48 & Methylphenidate & 0.05 mg/kg A.M. & 56 & 57 & 85 & 73 & 0 & 0 \\
\hline 9 & 68 & Methylphenidate & $0.15 \mathrm{mg} / \mathrm{kg}$ A.M. & 58 & $67^{\mathrm{a}}$ & 92 & 92 & 42 & 17 \\
\hline 9 & 60 & Dextroamphetamine & $0.30 \mathrm{mg} / \mathrm{kg}$ A.M. & 58 & $66^{\mathrm{a}}$ & 85 & 96 & 1 & 2 \\
\hline 9 & 48 & Dextroamphetamine & $0.10 \mathrm{mg} / \mathrm{kg}$ A.M. & 51 & 55 & 88 & 80 & 0 & 0 \\
\hline 10 & 42 & Methylphenidate & $0.20 \mathrm{mg} / \mathrm{kg}$ A.M. & 50 & 57 & 87 & 58 & $<1$ & 0 \\
\hline 10 & 52 & Methylphenidate & $0.45 \mathrm{mg} / \mathrm{kg}$ daily & 60 & $71^{\mathrm{b}}$ & 55 & 38 & 0 & 0 \\
\hline 10 & 44 & Dextroamphetamine & Daily $^{\mathrm{c}}$ & $66^{\mathrm{a}}$ & $66^{\mathrm{a}}$ & 93 & 69 & 2 & 32 \\
\hline 11 & 42 & Methylphenidate & $0.25 \mathrm{mg} / \mathrm{kg}$ A.M. & 62 & $67^{\mathrm{a}}$ & 91 & 93 & 0 & 11 \\
\hline
\end{tabular}

CBCL $T$ scores ranges: normal $(<65)$

${ }^{\text {a }}$ Borderline (65-69), CBCL $T$ scores range

${ }^{\mathrm{b}}$ Clinical (>69), CBCL $T$ scores range

${ }^{\mathrm{c}}$ Dosage for one participant was missing due to incomplete parent report 
significant range $(n=2)$. On the DSM-ADHD scale, which uses items specifically aligned with DSM-IVADHD criteria to screen for a potential ADHD diagnosis, participants had an average T-score of 58 (range 50-69) with $17 \%$ falling in the borderline range $(n=2)$ and none in the clinically significant range (see Table 1). Notably, the attention problems subscale has demonstrated relatively high diagnostic accuracy (Chen et al. 1994; Ebesutani et al. 2010), and both the attention problems and DSM-ADHD subscales have been shown to significantly discriminate children with ADHD from children with other disruptive behavior disorders (Ebesutani et al. 2010). See Table 1 for CBCL DSM-ADHD and attention problems subscales scores.

\section{Measures}

Multiple measures of treatment efficacy were obtained including behavioral, academic performance, and physiological arousal.

Behavior: attention and motor activity Attention and motor activity were coded from direct observation of videotaped assessment sessions. Each session consisted of administration of a standardized academic achievement test lasting approximately $30 \mathrm{~min}$. Attention was defined as being ontask (i.e., active engagement in answering the questions) or off-task (i.e., not following instructions, making comments unrelated to the test). Motor activity was defined as either being in-seat or out-of-seat during test administration. For both attention and motor activity, continuous coding was used based on 3-s interval. The percent of time boys were attending and were in their seat were the two dependent variables.

Academic performance Academic performance was measured using comparable, yet distinct forms (forms A and B), of the Woodcock-Johnson Psycho-Educational BatteryRevised (WJ-R; Woodcock et al. 1990). The broad knowledge cluster score was used rather than math and reading scores because the majority of participants could not achieve a basal on those subtests. The WJ-R provides standard scores, age and grade equivalents, and $W$ scores. $W$ scores are equal-interval derived Rasch scores with a mean of approximately 500 for fifth graders (Woodcock et al. 1990). Test-retest reliabilities for the clusters exceed 0.86 for all age groups (Sattler 1990). The dependent variables for academic performance were the age equivalent and $W$ scores on the broad knowledge cluster.

Physiological arousal Heart activity was collected using the Mini-Log 2,000 W and edited with MxEdit (Mini Mitter Company 2000; Porges 1994). Sessions started with a 10-min adaptation period (i.e., subjects were shown an age-appropriate videotape). The last $5 \mathrm{~min}$ of the adaptation period was used as a baseline. Immediately following the baseline, the participants completed the academic testing. Dependent variables for heart activity included inter-beatinterval (IBI) and vagal tone for three conditions: baseline, academic testing, and modulation (baseline-academic testing). Data from two subjects were not available because one subject refused to wear the equipment, and data from one subject contained an excessive number of artifacts.

Intelligence quotient Nonverbal mental age was measured using the Leiter International Performance Scale-Revised (Leiter-R; Roid and Miller 1997). According to the test publishers, the internal consistency of the Leiter-R ranges from 0.87 to 0.93 (Roid and Miller 1997). A brief IQ score was derived from four subtests in the visualization and reasoning battery (figure ground, form completion, sequential order, and repeated patterns).

\section{Procedures}

Participants were assessed on consecutive days and were on medication for 1 day and off medication for the other day. The order of medication status was altered sequentially, starting with the first participant off medication the first day and alternating with each subsequent participant to prevent order effects; thus, half of the boys were on medication on the first day, and half were on medication on the second day. Based on parental report, all children were medication free for a minimum of $12 \mathrm{~h}$ prior to the onset of the "off medication" condition to ensure that effects of the stimulant were removed given their short half-life. A child psychiatrist with expertise in psychopharmacological treatment of children with FXS was a consultant for these decisions (see Acknowledgements). Trained research assistants used The Noldus Observer software (Noldus Information Technology 2003) to code the participant behavior. Behavioral coders were blind to treatment status and were therefore not informed as to whether the participants were on or off medication in the videos. Coders were trained to 0.80 reliability or higher (based on a 1-s window of agreement) before coding began, and reliability was maintained at 0.80 or better for $20 \%$ of the data. Reliability estimates were 0.88 for attention and 0.99 for motor activity.

\section{Analyses}

Data were analyzed using both paired $t$ tests and nonparametric Wilcoxon tests due to the small sample size and non-normal distributions. These two tests produced comparable results across analyses, thus only paired sample $t$ tests are reported in text. See Table 2 for descriptive 
statistics and a comparison of paired sample $t$ tests and nonparametric Wilcoxon test results. Correlational analyses were used to evaluate the relationship of change scores in participants' behavior (on medication-off medication) with age and IQ. Observed and expected concordance were calculated and compared to inform the independence of effects across variables.

\section{Results}

Effect of stimulant treatment

Attention Results indicated that participants were more attentive when they were on medication, $t(11)=2.70$, $p=0.02$. Examination of individual profiles revealed that nine of the participants $(75 \%)$ showed improved attention, two participants showed decreased attention and one showed no change. Within the group showing improved attention, the average percent improvement was 35\% (range 15-68\%). Using guidelines from previous research (Aman et al. 2003; Pearson et al. 2004), eight participants showed moderate improvement $(>15 \%)$, and five participants showed significant improvement ( $>30 \%$; see Fig. 1). Change scores in percentage of on-task behavior did not correlate with age $(r=-0.001, p=0.99)$ or IQ $(r=-0.23, p=0.47)$.

Motor movement There was no difference in motor activity when participants were on medication $t(11)=$ $0.001, p=0.99$. Although case 10 represented an outlier with an unusually high rate of out-of-seat time, the difference between groups was still nonsignificant when the outlier was removed from analyses $(p=0.65)$. Individual profiles showed that three participants $(25 \%)$ showed decreased activity, six showed no change, and three showed increased activity while on medication. Change scores in percentage of on-task behavior did not correlate with age $(r=-0.39, p=0.20)$. However, there was a positive correlation between IQ and change score of percent of time spent out-of-seat $(r=0.67, p=0.02)$, with higher IQ corresponding with higher increases in of out- of-seat behavior. However, due to the nonsignificant group differences in motor movement on and off medication, the small sample size, and the descriptive nature of correlational analyses; this result should be interpreted with caution.

Academic performance $W$ scores, $t(11)=2.89, p=0.015$, and age equivalents, $t(11)=3.15, p=0.009$, on the broad knowledge cluster of the WJ-R were higher when participants were on medication. Individual profiles suggested that nine of the participants (75\%) improved in both the $W$ and age-equivalent scores, two declined in performance and one showed no change.

Physiological arousal Results indicate that baseline IBI and mean IBI during the WJ-R were not different on medication (all $p>0.05$ ). However, modulation of IBI was greater when on medication, $t(9)=2.54, p=0.03$. Individual profiles suggested that seven of the participants $(70 \%)$ had lengthened IBI when on medication, contributing to the significant group difference in modulation. Baseline vagal tone, mean vagal tone during the $\mathrm{WJ}-\mathrm{R}$, and vagal modulation were not different based on medication status ( $p>0.05$ for all measures). Individual profiles suggested that six participants $(60 \%)$ displayed increased vagal tone when on medication, with four displaying decreased vagal tone.

\section{Independence of effects across variables}

Similar to the model set by Pearson et al. (2004), we compared individual patterns of concordance among attention, academic performance, and physiological arousal to determine whether medication-related change occurs independently within each variable. For these analyses, participants who improved across all three measures were identified as positively concordant $(n=5)$, and participants who did not improve were identified as negatively concordant $(n=1)$. Participants with inconsistent response patterns $(n=4)$ or missing data $(n=2)$ were
Table 2 Behavior, academic performance, and physiological arousal regulation results

\begin{tabular}{|c|c|c|c|c|c|c|c|c|}
\hline \multirow[t]{2}{*}{ Paired sample } & \multicolumn{2}{|c|}{ On medication } & \multicolumn{2}{|c|}{ Off medication } & \multicolumn{2}{|c|}{ Paired sample test } & \multicolumn{2}{|c|}{ Wilcoxon test } \\
\hline & $M$ & $S D$ & $M$ & $S D$ & $t$ & $p$ & $z$ & $p$ \\
\hline Percent on task behavior & 83.05 & 13.42 & 69.81 & 16.54 & 2.69 & 0.02 & -2.20 & 0.03 \\
\hline Percent out of seat & 13.92 & 26.38 & 13.87 & 18.54 & 0.0009 & 0.99 & -0.36 & 0.72 \\
\hline WJ-R $W$ score & 456.83 & 19.04 & 450.25 & 19.34 & 2.89 & 0.02 & -0.23 & 0.02 \\
\hline WJ-R age equivalent & 64.08 & 19.29 & 57.67 & 18.22 & 3.15 & 0.009 & -2.45 & 0.01 \\
\hline Interbeat interval & 23.50 & 20.27 & 3.50 & 20.97 & 2.54 & 0.03 & -1.89 & 0.06 \\
\hline Vagal tone & 0.22 & 1.40 & -0.10 & 0.54 & 0.67 & 0.52 & -0.36 & 0.72 \\
\hline
\end{tabular}


Fig. 1 Box plots of attention and activity. The box spans the 25 th to 75 th percentile and the median is indicated as a line within the box. Results did not significantly differ between analyses conducted with and without the outlier (asterisk)

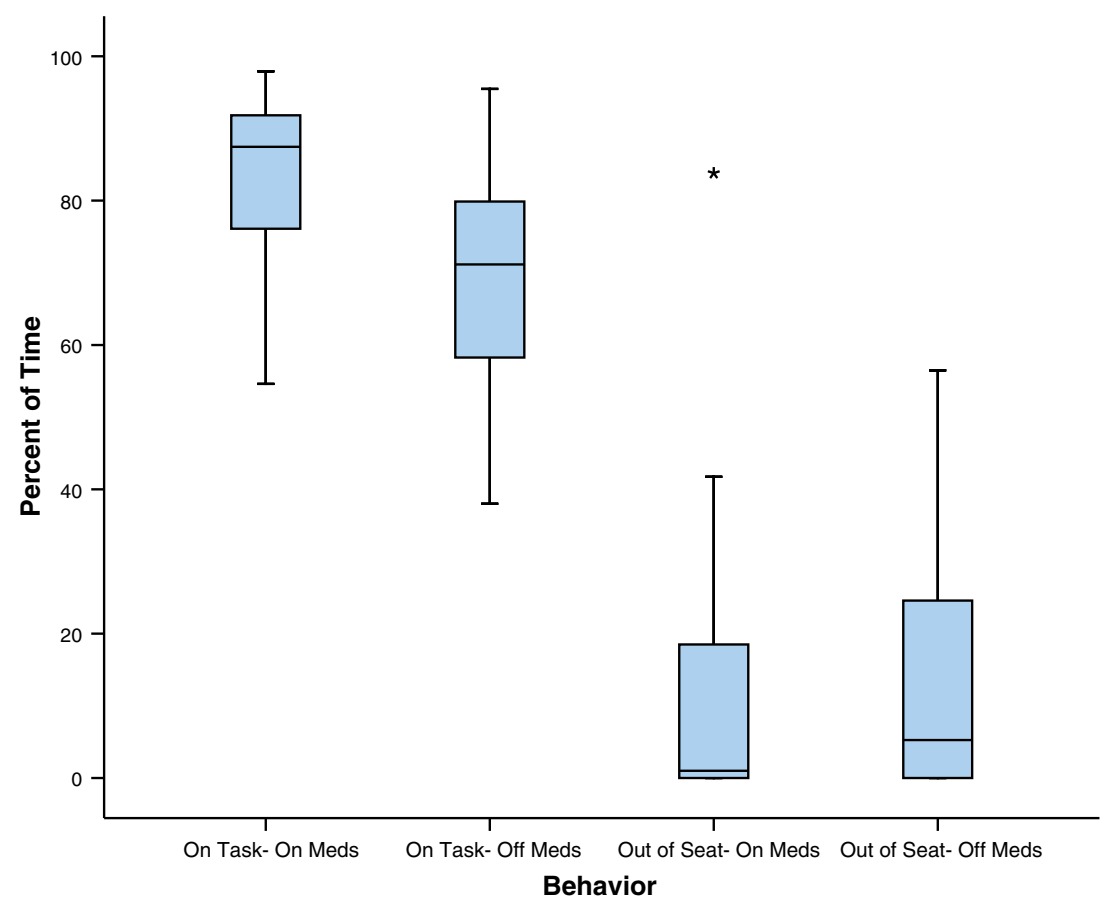

excluded from the analyses. In an independent sample, the expected concordance rate is calculated by multiplying the positive response rate (RR) across variables. In our sample, the expected concordance across attention $(\mathrm{RR}=0.75)$, academic performance $(\mathrm{RR}=0.75)$, and physiological arousal $(\mathrm{RR}=0.70)$ is calculated as $0.75 \times 0.75 \times$ $0.70=0.39$. The actual concordance rate in our sample is 0.6 , indicating these three variables may not be operating independently. Paired comparisons revealed unexpectedly high observed concordance across attention and academic performance $($ expected $=0.56$, observed $=0.67$ ), attention and physiological arousal (expected $=0.53$, observed $=$ 0.70 ), and academic performance and physiological arousal (expected $=0.53$, observed $=0.70$ ). Although all observed concordance rates were higher than expected, comparisons involving physiological arousal showed the most elevated rates, suggesting arousal may significantly relate to measures of academic performance and attention in our sample.

\section{Discussion}

The majority of boys with FXS display poor attention and elevated activity compared to typically developing and ageand IQ-matched controls. Stimulant medication is widely prescribed to treat these symptoms, yet few extant studies examine treatment efficacy. Treatment efficacy in boys with FXS is critical given that most children have intellectual handicaps compounded by poor attention disproportionate to their mental age. This study examined multiple indices of treatment efficacy and their concordance, the magnitude of treatment response, and predictors of treatment response in young boys with FXS to increase understanding of the efficacy of stimulant medication.

Our results suggest a response rate of $75 \%$ for improved attention when young boys with FXS were on stimulant medication. Our rate is remarkably consistent with previous response rates of $67 \%$ for teacher checklists of attention (Hagerman et al. 1988) and $75 \%$ for parent surveys (Berry-Kravis and Potanos 2004). In children with ADHD without co-morbid intellectual disability, the response rate to stimulant medication treatment is $75 \%$ (Group MToAGMC 2004). In contrast, response rates cluster at 50\% for children with ADHD and autism spectrum disorder (Scahill and Pachler 2007; Handen and Gilchrist 2006) or non-specific intellectual disability (Aman et al. 1996, 2003; Pearson et al. 2004) with a higher than expected rate of side effects reported in most studies (Barkley et al. 1990; Handen et al. 2000; Research Units on Pediatric Psychopharmacology (RUPP) Autism Network 2005). Thus, results from previous research in this area (Hagerman et al. 1988; Berry-Kravis et al. 2003) and the present study suggest that boys with FXS respond favorably to stimulant medication with response rates approximating that of typically developing children with ADHD exceeding rates reported for children with non-specific intellectual disability and autism spectrum disorder.

In addition to identifying a $75 \%$ response rate in improved attention in our sample, we report that $89 \%$ $(n=8 / 9)$ showed moderate gains and 56\% (5/9) showed significant gains. As with response rates, the magnitude 
of gains found in FXS is similar to levels described in children with ADHD and no co-morbid condition (MTA Cooperative Group 2004), yet is higher than levels of significant gains ranging from $37 \%$ to $44 \%$ for children with non-specific intellectual disability of approximately the same age and dose of methylphenidate (Aman et al. 2003; Pearson et al. 2004). To our knowledge, this is the first study to examine the magnitude of response and the association among measures as treatment effect to stimulant medication in FXS.

Unlike these positive effects of stimulants on attention, we did not find a reduction in motor activity when boys were on stimulant medication, consistent with the single behavioral observation study of stimulant medication use in boys with FXS (Hagerman et al. 1988). While our results could reflect our narrow definition of motor activity, Hagerman et al. (1988) used multiple measures of motor activity including an actometer and behavioral observations of fidgeting and out-of-seat activity and found no differences across medication conditions. A lack of treatment effect on motor activity could reflect the age range of our subjects, as hyperactivity decreases with age in FXS (Berry-Kravis and Potanos 2004) and reduced motor activity in response to stimulant medication treatment might be specific to young children (Handen et al. 1999) or certain tasks (Aman et al. 2003).

We found a response rate of $75 \%$ for improved academic performance in our sample and an association between attention and academic performance. Our research is the first to examine the effect of medication on academic performance in FXS, demonstrating that stimulants may improve attention and academic performance. It is important to note that our study demonstrated improved academic performance rather than improved learning, which would have to be evaluated using a longitudinal well-controlled design. However, our standardized measure of academic performance may be seen as a more direct or functional outcome compared to lab-based measures (e.g., continuous performance measures) that are often criticized as having questionable generalizability to "real world" settings. Given the importance of academic performance in determining educational and vocational opportunities, our findings suggest that stimulant medication may enable boys with FXS to perform to their best ability on standardized or classroom based exams. Therapeutic services and educational programming decisions are often based on test results, making our findings particularly relevant.

We also report increased physiological regulation of IBI, but not vagal tone, with stimulus medication treatment. IBI is influenced by both parasympathetic and sympathetic activity, whereas vagal tone indicates parasympathetic activity (Vaughan Van Hecke et al. 2009). Thus, our results are consistent with previous research suggesting stimulant medication affects sympathetic arousal in individuals with FXS (Hagerman et al. 2002). These findings lend support to a general pattern of blunted arousal regulation that has been increasingly reported in association with poor cognitive outcomes in children and adults with FXS (Kwon et al. 2001; Roberts et al. 2001, 2008). Unlike work with children with non-specific intellectual disability and ADHD that reflects independence of cognitive and behavioral function (Pearson et al. 2004), our results suggest that arousal regulation, attention, and academic performance are interrelated in FXS.

The hypoarousal model for children with ADHD (without intellectual disability) suggests that their baseline arousal levels are generally low, and stimulants work to increase arousal to normal levels resulting in improved cognitive and behavior regulation (Lawrence et al. 2005; Oades et al. 2005). In contrast, FXS is associated with hyperarousal and exaggerated responsivity (Miller et al. 1999; Roberts et al. 2001; Hessl et al. 2001), which is not generally associated with children with intellectual disabilities (Zentall and Zentall 1983). In both previous research (Hagerman et al. 2002) and the present study, baseline levels of arousal do not appear affected by stimulant medication. Rather, a normalized degree of arousal modulation is reported, which contrasts to results showing an increase in baseline arousal in children with non-specific intellectual disabilities (Aman et al. 2003). Thus, stimulant medication is associated with increased arousal in children with ADHD and non-specific intellectual ability, whereas stimulant medication is associated with reduced arousal hyper-reactivity in FXS. This relationship is reflected in our finding that stimulants are associated with cardiovascular modulation of sympathetic (IBI), not parasympathetic (vagal tone), arousal in children with FXS. While clearly speculative, arousal dysfunction may be one of the primary variables that discriminates stimulant treatment effects in children with FXS and ADHD to other children with ADHD with and without disabilities. This conclusion is partially supported by evidence of the inter-relationship of arousal to attention and academic performance in this study and is directly supported by the work by Hagerman et al. (2002) showing that arousal regulation was the treatment outcome that differentiated children with FXS/ADHD from children with non-specific intellectual disability and ADHD.

Previous work has shown that younger children and those with more severe intellectual disabilities were less responsive to stimulant medication treatment (Aman et al. 2003). Although we found a positive correlation between IQ and increased out-of-seat behavior on medication, the lack of group differences in motor movement across medication status indicate this result may reflect the heterogeneity of our small sample rather than a clinically 
meaningful effect. We did not find a relationship between chronological age with stimulant medication treatment nor did we find a relationship between IQ and on-task behavior in our sample, despite the similar mean IQ levels chronological ages between our study and existing work (Aman et al. 2003). However, the range of IQs and age was considerably more varied in other studies and the samples were larger (Aman et al. 2003), suggesting that our findings may be limited by our small sample size and relative homogeneity of IQ and age.

Limitations and future directions

While this study included a well-defined sample using multiple indices of objective treatment effects, there are a number of limitations. First, the sample is small, limiting our analyses and generalizability. In addition, we did not include a comparison group or restrict medication use to one type of stimulants. Our subjects were also on a relatively low dose of medication (mean of $0.19 \mathrm{mg} / \mathrm{kg}$, range of $0.05-0.45$ for methylphenidate), we did not have dosage information for one participant, and dosage was not a control variable in the design. Future studies should include a larger sample of boys and a sufficient sample of girls to draw gender comparisons. Additionally, the differential effects of medication across ADHD subtypes should be evaluated. Finally, longitudinal studies with a doubleblind placebo-controlled crossover design and multiple dose levels of medication are needed to examine efficacy of stimulant and other medication treatment effects.

\section{Summary and implications}

Preliminary evidence from our current study and existing work contribute information towards the development of a psychopharmacological phenotype for FXS based on the supposition that specific gene dysfunction may lead to specific neuroanatomical and neurochemical changes (Hagerman 1999). Specifically, we report a response rate of $70-75 \%$ in attention, academic performance and arousal regulation, a high concordance across multiple measures, and a significant gain in performance as treatment outcomes of stimulant medication in our sample of boys with FXS. In the case of FXS, we hypothesize that the FMR1 gene dysfunction leads to FMRP reduction and abnormal dendritic pruning associated with abnormal functioning of the prefrontal cortex resulting in poor attention and hyperarousal. While preliminary, our findings and others suggest that stimulant medication treatment outcomes in FXS may be unique in terms of a higher response rate, greater magnitude of response, and greater concordance among measures compared to outcomes for children with autism spectrum disorder and non-specific intellectual disabilities. While replication is needed, these findings contribute to the development of a psychopharmacological phenotype for FXS that could help guide treatment efforts (Hagerman 1999).

Acknowledgments This study was conducted by support from the FRAXA Research Foundation and by grant P30-HD003110-35S1. We would like to thank Dr. Michael Tranfaglia for his consultation on this study.

Conflicts of interest None

\section{References}

Achenbach TM. Manual for the child behavior checklist/4-18 and 1991 profile. Burlington, VT: University of Vermont Department of Psychiatry; 1991.

Achenbach TM, Rescorla LA. Manual for the ASEBA school-age forms and profiles. Burlington, VT: University of Vermont, Research Center for Children, Youth, and Families; 2001.

Aman MG, Pejeau C, Osborne P, Rojahn J, Handen B. Four-year follow-up of children with low intelligence and ADHD. Res Dev Disabil. 1996;17(6):417-32.

Aman MG, Buican B, Arnold LE. Methylphenidate treatment in children with borderline IQ and mental retardation: analysis of three aggregated studies. J Child Adolesc Psychopharmacol. 2003;13(1):29-40.

Amaría RN, Billeisen LL, Hagerman RJ. Medication use in fragile X syndrome. Ment Health Aspect Dev Disabil. 2001;4:143-7.

Backes M, Genc B, Schreck J, Doerfler W, Lehmkuhl G, von Gontard A. Cognitive and behavioral profile of fragile $\mathrm{X}$ boys: correlations to molecular data. Am J Med Genet. 2000;95(2):150-6.

Bailey Jr DB, Hatton DD, Skinner M. Early developmental trajectories of males with fragile $\mathrm{X}$ syndrome. Am J Ment Retard. 1998;103(1):29-39.

Barkley RA, McMurray MB, Edelbrock CS, Robbins K. Side effects of methylphenidate in children with attention deficit hyperactivity disorder: a systemic, placebo-controlled evaluation. Pediatrics. 1990;86(2):184-92.

Baumgardner TL, Reiss AL, Freund LS, Abrams MT. Specification of the neurobehavioral phenotype in males with fragile $\mathrm{X}$ syndrome. Pediatrics. 1995;95(5):744-52.

Berry-Kravis E, Potanos K. Psychopharmacology in fragile X syndrome - present and future. Ment Retard Dev Disabil Res Rev. 2004;10(1):42-8.

Berry-Kravis E, Lewin F, Wuu J, Leehey M, Hagerman R, Hagerman $\mathrm{P}$, et al. Tremor and ataxia in fragile $\mathrm{X}$ premutation carriers: blinded videotape study. Ann Neurol. 2003;53(5):616-23.

Berry-Kravis E, Sumis A, Hervey C, Nelson M, Porges SW, Weng N, et al. Open-label treatment trial of lithium to target the underlying defect in fragile X syndrome. J Dev Behav Pediatr. 2008;29 (4):293-302.

Berry-Kravis E, Hessl D, Coffey S, Hervey C, Schneider A, Yuhas J, et al. A pilot open label, single dose trial of fenobam in adults with fragile X syndrome. J Med Genet. 2009;46(4):266-71.

Bilousova TV, Dansie L, Ngo M, Aye J, Charles JR, Ethell DW, et al. Minocycline promotes dendritic spine maturation and improves behavioural performance in the fragile $\mathrm{X}$ mouse model. J Med Genet. 2009;46(2):94-102. 
Chen WJ, Faraone SV, Biederman J, Tsuang MT. Diagnostic accuracy of the Child Behavior Checklist scales for attention-deficit hyperactivity disorder: a receiver-operating characteristic analysis. J Consult Clin Psychol. 1994;62(5):1017-25.

Comery TA, Harris JB, Willems PJ, Oostra BA, Irwin SA, Weiler IJ, et al. Abnormal dendritic spines in fragile $\mathrm{X}$ knockout mice: maturation and pruning deficits. Proc Natl Acad Sci U S A. 1997;94(10):5401-4.

Ebesutani C, Bernstein A, Nakamura BJ, Chorpita BF, Higa-McMillan CK, Weisz JR. Concurrent validity of the Child Behavior Checklist DSM-Oriented Scales: correspondence with DSM Diagnoses and comparison to Syndrome Scales. J Psychopathol Behav Assess. 2010;32(3):373-84.

Erickson CA, Weng N, Weiler IJ, Greenough WT, Stigler KA, Wink LK, et al. Open-label Riluzole in fragile X syndrome. Brain Res. 2011;22(1380):264-70.

Freund LS, Reiss AL, Abrams MT. Psychiatric disorders associated with fragile $X$ in the young female. Pediatrics. 1993;91(2):321-9.

Fryns JP. X-linked mental retardation. Medical genetics: past present, and future. New York: Liss; 1985. p. 309-19.

Hagerman RJ. Psychopharmacological interventions in fragile $\mathrm{X}$ syndrome, fetal alcohol syndrome, Prader-Willi syndrome, Angelman syndrome, Smith-Magenis syndrome, and velocardiofacial syndrome. Ment Retard Dev Disabil Res Rev. 1999;5:305-13.

Hagerman RJ. The physical and behavioral phenotype. In: Hagerman PJ, Hagerman AE, editors. Fragile X syndrome: diagnosis, treatment, and research. 3rd ed. Baltimore: Johns Hopkins University; 2002. p. 3-109.

Hagerman RJ, Murphy MA, Wittenberger MD. A controlled trial of stimulant medication in children with the fragile $\mathrm{X}$ syndrome. Am J Med Genet. 1988;30(1-2):377-92.

Hagerman RJ, Hull CE, Safanda JF, Carpenter I, Staley LW, O'Connor RA, et al. High functioning fragile $\mathrm{X}$ males: demonstration of an unmethylated fully expanded FMR-1 mutation associated with protein expression. Am J Med Genet. 1994;51(4):298-308.

Hagerman RJ, Miller LJ, McGrath-Clarke J, Riley K, Goldson E, Harris SW, et al. Influence of stimulants on electrodermal studies in fragile X syndrome. Microsc Res Tech. 2002;57(3):168-73.

Handen BL, Gilchrist R. Practitioner review: psychopharmacology in children and adolescents with mental retardation. J Child Psychol Psych. 2006;47(9):871-82.

Handen BL, Feldman HM, Lurier A, Murray PJ. Efficacy of methylphenidate among preschool children with developmental disabilities and ADHD. J Am Acad Child Adolesc Psych. 1999;38(7):805-12.

Handen BL, Johnson CR, Lubetsky M. Efficacy of methylphenidate among children with autism and symptoms of attentiondeficit hyperactivity disorder. J Autism Dev Disord. 2000;30 (3):245-55.

Hayashi ML, Rao BS, Seo JS, Choi HS, Dolan BM, Choi SY, et al. Inhibition of p21-activated kinase rescues symptoms of fragile $\mathrm{X}$ syndrome in mice. Proc Natl Acad Sci U S A. 2007;104(27):11489-94.

Hessl D, Dyer-Friedman J, Glaser B, Wisbeck J, Barajas RG, Taylor $\mathrm{A}$, et al. The influence of environmental and genetic factors on behavior problems and autistic symptoms in boys and girls with fragile X syndrome. Pediatrics. 2001;108(5):E88.

Kwon H, Menon V, Eliez S, Warsofsky IS, White CD, Dyer-Friedman $\mathrm{J}$, et al. Functional neuroanatomy of visuospatial working memory in fragile $\mathrm{X}$ syndrome: relation to behavioral and molecular measures. Am J Psychiatry. 2001;158(7):1040-51.

Lawrence CA, Barry RJ, Clarke AR, Johnstone SJ, McCarthy R, Selikowitz M, et al. Methylphenidate effects in attention deficit/ hyperactivity disorder: electrodermal and ERP measures during a continuous performance task. Psychopharmacology (Berl). 2005;183(1):81-91.
Loesch DZ, Huggins RM, Hagerman RJ. Phenotypic variation and FMRP levels in fragile X. Ment Retard Dev Disabil Res Rev. 2004;10(1):31-41.

Miller LJ, McIntosh DN, McGrath J, Shyu V, Lampe M, Taylor AK, et al. Electrodermal responses to sensory stimuli in individuals with fragile X syndrome: a preliminary report. Am J Med Genet. 1999;83(4):268-79.

Mini Mitter Company 2000 W. Windows Version 1.2 ed. Oregon2001.

MTA Cooperative Group. National Institute of Mental Health Multimodal Treatment Study of ADHD follow-up: changes in effectiveness and growth after the end of treatment. Pediatrics 2004;113(4):762-9.

Noldus Information Technology. The Observer, Computer software and manual. 5 ed. The Netherlands 2003.

Oades RD, Sadile AG, Sagvolden T, Viggiano D, Zuddas A, Devoto P, et al. The control of responsiveness in ADHD by catecholamines: evidence for dopaminergic, noradrenergic and interactive roles. Dev Sci. 2005;8(2):122-31.

Ornstein PA, Schaaf JM, Hooper SR, Hatton DD, Mirrett P, Bailey DB Jr. Memory skills of boys with fragile X syndrome. Am J Ment Retard. 2008;113(6):453-65.

Paribello C, Tao L, Folino A, Berry-Kravis E, Tranfaglia M, Ethell IM, et al. Open-label add-on treatment trial of minocycline in fragile $\mathrm{X}$ syndrome. BMC Neurol. 2010;10:91.

Pearson DA, Lane DM, Santos CW, Casat CD, Jerger SW, Loveland KA, et al. Effects of methylphenidate treatment in children with mental retardation and ADHD: individual variation in medication response. J Am Acad Child Adolesc Psych. 2004;43(6):686-98.

Porges SW. MXedit V2.21 Beta. Bethesda, MD: Delta Biometrics, Inc; 1994.

Research Units on Pediatric Psychopharmacology (RUPP) Autism Network. Randomized, controlled, crossover trial of methylphenidate in pervasive developmental disorders with hyperactivity. Arch Gen Psychiatry. 2005;62(11):1266-74.

Riley K, Ikle LO, Hagerman RJ. A randomized, double-blind comparative trial of Adderall in the treatment of attention deficit disorder in children with fragile X. 7th International Fragile X Conference; July 19-23; Los Angeles 2000.

Roberts JE, Boccia ML, Bailey Jr DB, Hatton DD, Skinner M. Cardiovascular indices of physiological arousal in boys with fragile X syndrome. Dev Psychobiol. 2001;39(2):107-23.

Roberts J, Mazzocco MM, Murphy MM, Hoehn-Saric R. Arousal modulation in females with fragile $\mathrm{X}$ or Turner syndrome. J Autism Dev Disord. 2008;38(1):20-7.

Roid GH, Miller LJ. Leiter International Performance Scale-revised. Wood Dale, IL: Stoelting Co; 1997.

Sattler JM. Assessment of academic achievement and special abilities. In Assessment of Children. 3rd ed. San Diego: Sattler; 1990.

Scahill L, Pachler M. Treatment of hyperactivity in children with pervasive developmental disorders. J Child Adolesc Psychiatr Nurs. 2007;20(1):59-62.

Staley-Gane L, Flynn L, Neitzel K, Cronister A, Hagerman RJ. Expanding the role of the genetic counselor. Am J Med Genet. 1996;64(2):382-7.

Sullivan K, Hatton D, Hammer J, Sideris J, Hooper S, Ornstein P, et al. ADHD symptoms in children with FXS. Am J Med Genet A. 2006;140(21):2275-88.

Torrioli MG, Vernacotola S, Peruzzi L, Tabolacci E, Mila M, Militerni R, et al. A double-blind, parallel, multicenter comparison of ${ }_{1}$-acetylcarnitine with placebo on the attention deficit hyperactivity disorder in fragile X syndrome boys. Am J Med Genet A. 2008;146(7):803-12.

Torrioli M, Vernacotola S, Setini C, Bevilacqua F, Martinelli D, Snape $\mathrm{M}$, et al. Treatment with valproic acid ameliorates ADHD symptoms in fragile $\mathrm{X}$ syndrome boys. Am J Med Genet A. 2010;152A(6):1420-7. 
Tsiouris JA, Brown WT. Neuropsychiatric symptoms of fragile X syndrome: pathophysiology and pharmacotherapy. CNS Drugs. 2004;18(11):687-703.

Turk J. The fragile-X syndrome. On the way to a behavioural phenotype. Br J Psychiatry. 1992;160:24-35.

Vaughan Van Hecke A, Bal E, Lamb D, Harden E, Kramer A, Denver J, et al. Electroencephalogram and heart rate regulation to familiar and unfamiliar people in children with autism spectrum disorders. Child Development. 2009;80 (4):1118-33.

Wang Y, Bowman D, Krum D, Coalho E, Smith-Jackson T, Bailey D, et al. Effects of video placement and spatial context presentation on path reconstruction tasks with contextualized videos. IEEE Trans Vis Comput Graph. 2008;14(6):1755-62.

Wang H, Kim SS, Zhuo M. Roles of fragile X mental retardation protein in dopaminergic stimulation-induced synapse-associated protein synthesis and subsequent alpha-amino-3-hydroxyl-5methyl-4-isoxazole-4-propionate (AMPA) receptor internalization. J Biol Chem. 2010;285(28):1888-901.

Weiler IJ, Greenough WT. Synaptic synthesis of the fragile X protein: possible involvement in synapse maturation and elimination. Am J Med Genet. 1999;83(4):248-52.

Woodcock RW, Mather N. In: Johnson RWWMB, editor. WoodcockJohnson Psycho-Educational Battery-revised. Itasca, IL: Riverside Pub; 1990.

Zeier ZKA, Bodhinathan K, Feller JA, Foster TC, Bloom DC. Fragile $\mathrm{X}$ mental retardation protein replacement restores hippocampal synaptic function in a mouse model of fragile $\mathrm{X}$ syndrome. Gene Ther. 2009;16(9):1122-9.

Zentall SS, Zentall TR. Optimal stimulation: a model of disordered activity and performance in normal and deviant children. Psychol Bull. 1983;94(3):446-71. 